\title{
POSITIVE THIGMOTROPISM OF CULEX PIPIENS IN HIBERNATION.
}

\author{
By Harry B. Weiss,
}

New Brunswick, N. J.

Commencing about the middle of September, gravid females of Culex pipiens become strongly negatively phototropic and seek dark hibernation quarters which in the cities consist of cellars, basements, closed empty houses and the like. They must however be dark. The activity of these hibernating individuals depends entirely upon the temperature of the cellar or other place selected. If the place be warm, they are quite active when disturbed and if cold they are more or less torpid. Positive thigmotropism is of course exhibited only by those hibernating in warm places.

After having become acclimated to these surroundings, the negative phototropism seems to be entirely supplanted by positive thigmotropism. Phototropic stimuli no longer produce responses. Upon being disturbed, they fly readily, but not far from their place of rest which is usually the lower side of a wall and always return to a similar position.

A shaft of sunlight manipulated by mirrors and thrown upon specimens in these positions produced absolutely no reactions. A sixteen candle-power electric light placed a foot away from specimens and allowed to remain there for an hour, also produced no response. The insects made no attempt to fly into a region of less illumination or from a less to a greater, but remained clinging to the wall. Of course it must be remembered that they were in a slightly dormant condition. Nevertheless they responded actively to mechanical stimuli.

In addition to being positively thigmotropic, gravid hibernating females of Culex pipiens are negatively geotropic. They always assume a position with the long axis of the body perpendicular to the earth and the head pointing upward. Never have I seen one in a different attitude.

The tropisms of $C$. pipiens are varied and interesting. Taking the female, we find her during the summer to be normally nega- 
tively phototropic. Those produced during the end of the season become strongly negatively phototropic and after entering into a state of partial hibernation, no longer react phototropically but instead become positively thigmotropic and negatively geotropic. Upon the approach of spring they become positively phototropic up to a low intensity and normally negatively phototropic and in addition positively chemotropic to certain stimuli. Herein is included the instinctive action of hibernation dependent upon or induced by several tropic stimuli.

\section{PECULIAR HABITS OF SMALL DIPTERA, DESMOMETOPA LATIPES MEIG.}

While collecting bees on the flowers of the wild aster on September 15, 1912, I noticed a small fly make a dash at a spider that was resting on a milkweed leaf. Closer examination showed that the spider was feeding on a plant bug, Lygus pratensis L., which was wholly hidden beneath the body of the spider. There were also three of the flies on the leaf an inch or so away, and occasionally one or all of them would rush in under the forelegs of the spider and cling to the body of the victim. They did not seem to mind the constantly moving forelegs and were only disturbed when the spider moved itself and prey bodily. Possibly they had to move to escape being jammed against the leaf. I was not able to make sure that they were lapping up the juices of the bug but $I$ have no doubt that this is the reason for their actions.

The fearlessness of these small insects, barely equal to the head of the spider, was astonishing to me and I can but wonder at the acquisition of such a habit of robbery from so formidable an enemy.

All the specimens were captured and submitted to Mr. C. W. Johnson who very kindly furnished the names of them. The spider is a female Phidippus multiformis Emerton, and the flies are Desmometopa latipes Meigen.

C. A. Frost. 

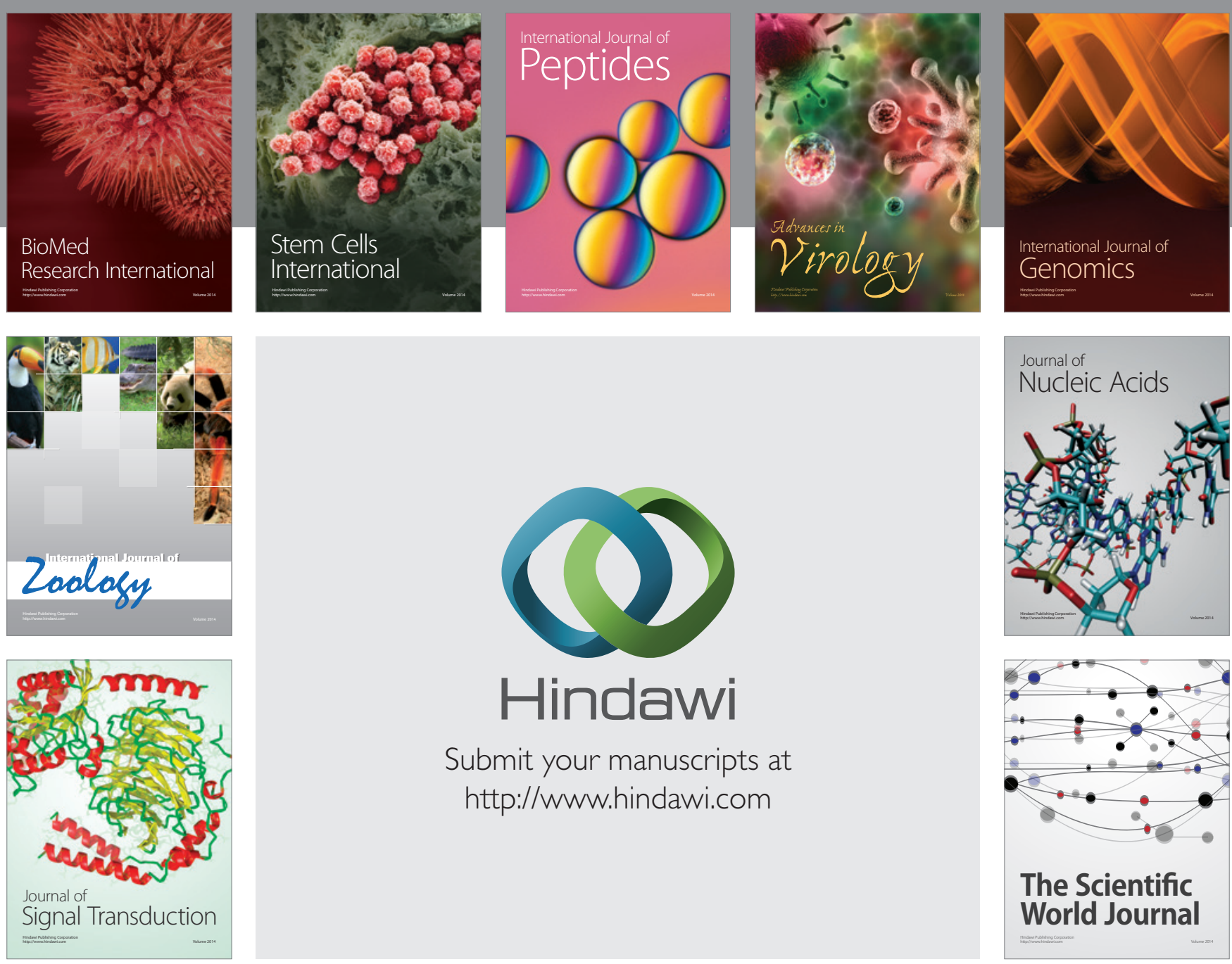

Submit your manuscripts at

http://www.hindawi.com
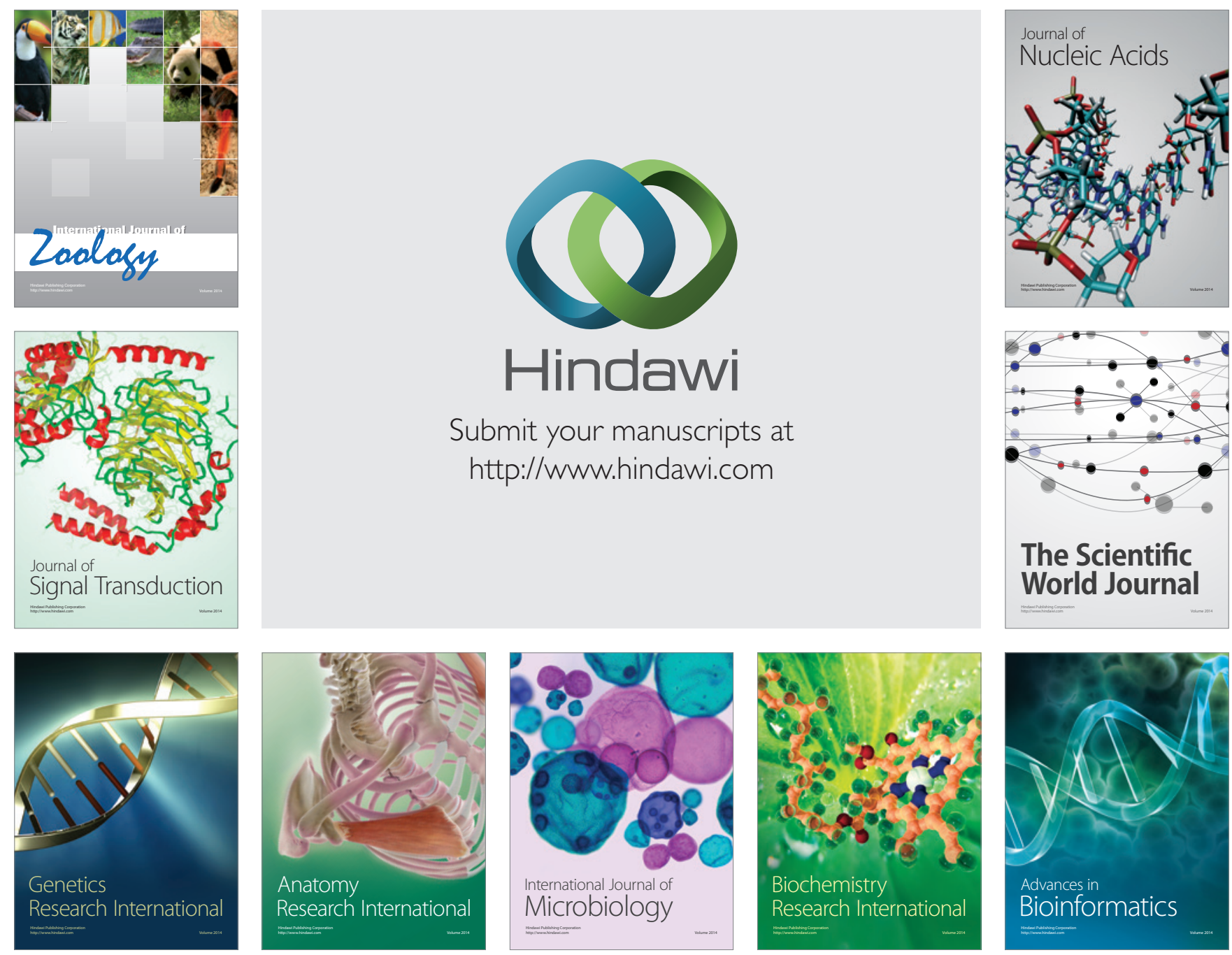

The Scientific World Journal
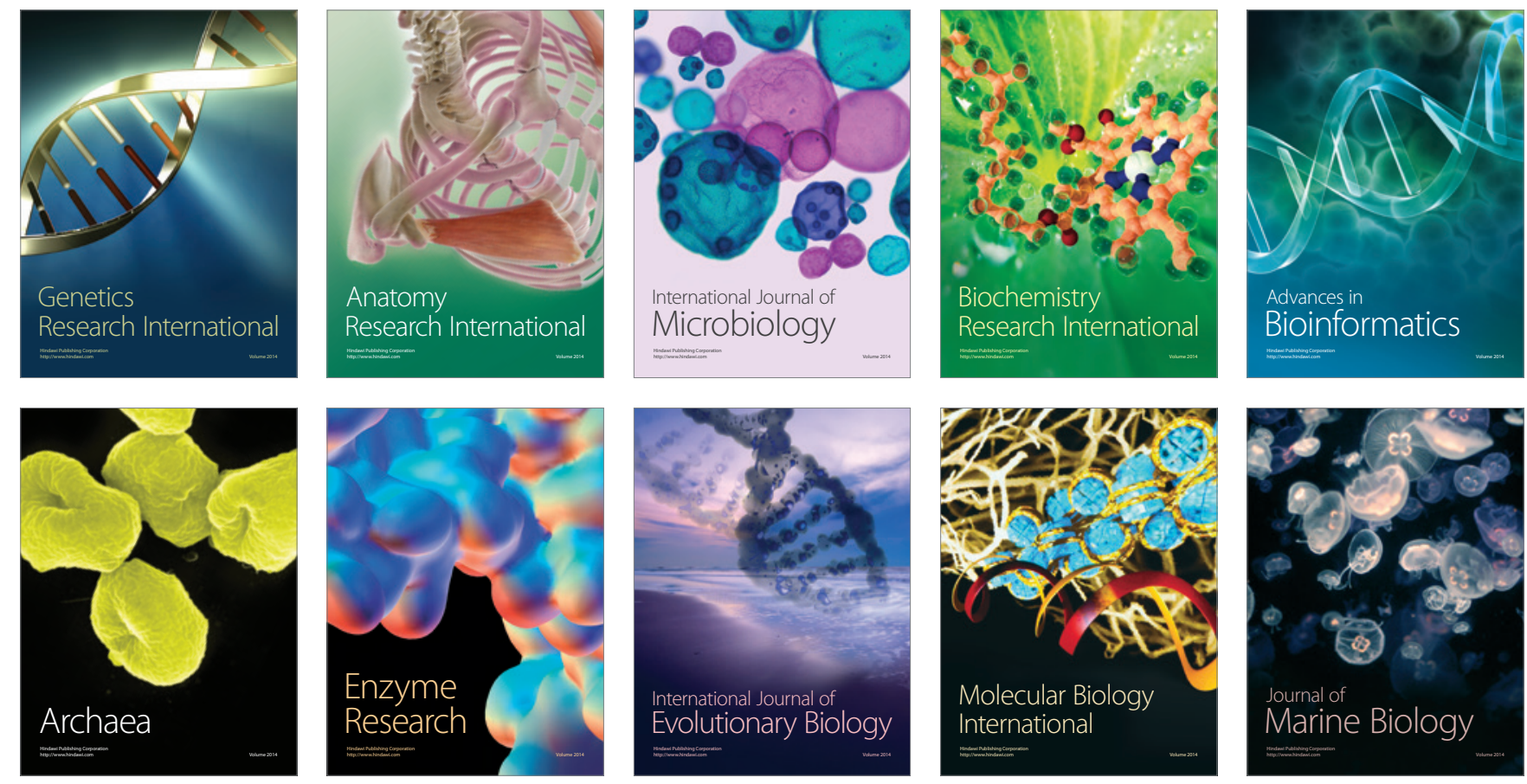